\title{
Risk Factors for Mortality Upper Digestive Haemorrhages at the University Hospital Centre of Brazzaville
}

\author{
Rody Stéphane Ngami1,2*, Pétula Moulene1, Jile Florient Mimiesse ${ }^{1,2}$, Arnaud Mongo-Onkouo ${ }^{1,2}$, \\ Ngala Akoa Itoua-Ngaporo',2, Marlyse Ngalessami', Péres Mardochée Motoula Latou', \\ Céline Sandra Adoua1, Philestine Clausina Mikolele Ahoui Apendi1,2, Deby Gassaye1,2, \\ Blaise Irénée Atipo Ibara',2, Jean-Rosaire Ibara ${ }^{1,2}$
}

${ }^{1}$ Department of Gastroenterology and Internal Medicine, Brazzaville University Hospital, Brazzaville, Congo

${ }^{2}$ Faculty of Health Sciences, Marien Ngouabi University, Brazzaville, Congo

Email: *rodyngami@gmail.com

How to cite this paper: Ngami, R.S., Moulene, P., Mimiesse, J.F., Mongo-Onkouo, A., Itoua-Ngaporo, N.A., Ngalessami, M., Latou, P.M.M., Adoua, C.S., Apendi, P.C.M.A., Gassaye, D., Ibara, B.I.A. and Ibara, J.-R. (2020) Risk Factors for Mortality Upper Digestive Haemorrhages at the University Hospital Centre of Brazzaville. Open Journal of Gastroenterology, 10, 341-348. https://doi.org/10.4236/ojgas.2020.1012033

Received: October 26, 2020

Accepted: December 26, 2020

Published: December 29, 2020

Copyright $\odot 2020$ by author(s) and Scientific Research Publishing Inc. This work is licensed under the Creative Commons Attribution International License (CC BY 4.0).

http://creativecommons.org/licenses/by/4.0/ (c) (i) Open Access

\begin{abstract}
In the absence of interventional endoscopy, the treatment of upper digestive haemorrhages (HDH) at Brazzaville University Hospital is essentially medicinal. The objective of this work was to identify the risk factors for $\mathrm{HDH}$ mortality at Brazzaville University Hospital by conducting a retrospective prognostic case-control study over a period of 2 years, from January 2017 to December 2018. The 180 patients included in the study for an HDH were divided into 2 groups according to their evolutionary modality: deceased patients (cases) and non deceased patients (controls). The mortality risk factors were studied by logistic regression. Mortality related to upper digestive haemorrhages was $36.6 \%$; the risk factors for death were age between 30 and 60 years with a (OR: 9.79; 95\% CI [1.24 - 76.83]; $\mathrm{p}=0.003$ ); male sex (OR: 2.03; 95\% CI [1.03 - 4]; $\mathrm{p}=0.0393$ ); late consultation beyond 24 hours (OR: 6.30; 95\% CI [2.12 - 18.72]; $\mathrm{p}=0.0009$ ), blood transfusions (OR: 3.5; 95\% CI [1.66 - 7.40]; $\mathrm{p}=0.0001)$. Protective factors were haemoglobin greater than $7 \mathrm{~g} / \mathrm{dL}$ (OR: 0.28 ; $95 \% \mathrm{CI}[0.14-0.54] ; \mathrm{p}=0.0001$ ); treatment with proton pump inhibitors (OR: 0.36; 95\% CI [0.15 - 0.84]; $\mathrm{p}=0.0191$ ). In conclusion, the reduction of the still high mortality rate in our country requires taking into account the identified risk factors and the acquisition of endoscopic haemostasis equipment.
\end{abstract}

\section{Keywords}

Upper Digestive Haemorrhage, Mortality, Haemostasis, Brazzaville 


\section{Introduction}

Upper digestive haemorrhages (HDH) are a medical-surgical emergency requiring rapid and appropriate treatment, often requiring endoscopic haemostasis. The prevalence of digestive haemorrhages varies from one country to another [1] [2] [3]. Itoundi-Bignoumba et al. in Gabon found mortality from upper digestive haemorrhage to be less than $3 \%$. This is also the case in many countries [3]-[11] practising endoscopic haemostasis where the mortality rate is less than $10 \%$. In countries with limited resources and no endoscopic haemostasis, mortality from digestive haemorrhages is around $30 \%-40 \%$, as shown by Ibara et al. in Congo Brazzaville which has no health insurance system and the treatment of digestive haemorrhages is mainly based on drugs such as proton pump inhibitors [12] [13] [14] [15]. In order to contribute to improving the management of upper gastrointestinal haemorrhages $(\mathrm{HDH})$, we carried out this work, the objectives of which were to determine the mortality rate from $\mathrm{HDH}$ and to identify the risk factors for mortality during $\mathrm{HDH}$.

\section{Patients and Methods}

This was a retrospective case-control prognostic study covering the period from 1 January 2017 to 31 December 2018, i.e. a two-year period. It was carried out in the Gastroenterology and Internal Medicine Department of Brazzaville University Hospital where patients hospitalised for digestive haemorrhages were admitted to an emergency unit but did not have access to endoscopic haemostasis facilities. We included all patients hospitalised in our department for upper GI haemorrhage during the study period. We used hospitalized patients' medical records to pather the necessary information for this study. Patients matched into two groups according to their evolutionary modality: deceased patients (cases) and living patients (controls). The sample size was calculated by Schwartz's formula ( $\mathrm{n} \geq \varepsilon 2 \mathrm{p}(1-\mathrm{p}) / \mathrm{i} 2$ ) with "I" being the precision at 0.01 , " $\mathcal{E}$ " at 1.96 for an alpha risk at 0.05 according to the reduced centred normal law, " $p$ " being the prevalence of $\mathrm{HDH}$. For an $\mathrm{HDH}$ prevalence of $6 \%$, the sample size was at least 92 patients. Data collection was carried out using a survey form respecting anonymity according to the agreement and recommendations of the national health sciences research ethics committee. The prognostic factors assessed were the same in both groups: demographic variables (age, sex), length of hospitalisation, previous intake of gastrotoxic drugs (anti-inflammatory drugs, platelet aggregation inhibitors, anticoagulants), presence of co-morbidity, haemoglobinemia, time to upper GI endoscopy, the pre-endoscopic ROCKALL score, the presence of hypovolemic shock, treatment with proton pump inhibitors (PPIs) at $8 \mathrm{mg} /$ hour, the need for transfusion, the number of red blood cells transfused, haemorrhagic recurrence. There was no conflict of interest in conducting this study. The data collected were entered and analysed on Epi info 7. Logistic regression was used to search for an association between prognostic factors and evolutionary modalities. The significance threshold was set at 5\% and the confidence interval at 95\%. 


\section{Results}

Out of 2741 patients were hospitalised, 180 were included, i.e. $6.56 \%$ of hospitalisations in our gastroenterology department. The average age was $54.24 \pm 17.55$ years, the extremes were 19 and 87 years. There were 61 women (34\%) and 119 men $(66 \%)$, i.e. a sex ratio of 1.95 . Upper GI endoscopy was performed in 130 patients, the endoscopic results were illustrated in Table 1, peptic ulcer was the primary cause of upper gastrointestinal bleeding. Sixty-six patients were deceased, 114 patients were alive. The mortality rate for upper GI haemorrhage was $36.6 \%$. The mean time to death was $2.75 \pm 1.38$ days, with extremes of 1 and 6 days. The causes of death were: hypovolemic shock in 55 cases (83.33\%), the presence of comorbidity (high blood pressure, kidney failure or diabetes mellitus) in 10 cases $(15.16 \%)$ and in 1 case (1.51\%); no cause was determined. Table 2 recapitulates the risk factors for death in bivariate analysis. Death was more frequent in patients aged between 30 and 60 years with a significant difference (Figure 1). Of the patients who died, 50 were male and 16 female with a significant difference (OR: 2.03; 95\% CI [1.03 - 4]; $\mathrm{p}=0.0393$ ). Previous intake of gastrotoxic drugs, observed in 98 patients of whom 30 had died, was not associated with death (OR: 0.56; 95\% CI [0.30 - 1.03], $\mathrm{p}=0.0665)$. A comorbidity was observed in 65 patients, 27 of whom had died, compared with 115 patients. The difference was not significant (OR: $1.38 ; 95 \%$ CI [0.74 - 2.59]; $p=0.3086$ ). The hospitalisation period was less than 24 hours in 37 patients, 4 of whom had died, and more than 24 hours in 143 patients, 62 of whom had died, with a significant difference (OR: 6.30; 95\% CI [2.12 - 18.72]; $\mathrm{p}=0.0009$ ). The pre-endoscopic Rockall score was not associated with the risk of death (OR: 1.54; 95\% CI [0.55 4.31]; $\mathrm{p}=0.4062$ ). Upper GI endoscopy was performed early (less than 24 hours after hospitalisation) in 24 patients of whom 2 had died and late in 106 of whom 18 had died without a significant difference (OR: 2.24; 95\% CI [0.48 - 10.42];

Table 1. Results of upper digestive endoscopy.

\begin{tabular}{ccc}
\hline Résults & $\mathbf{n}$ & $\%$ \\
Peptic ulcers & 57 & 41.01 \\
Signs of portal hypertension & 32 & 12.23 \\
No cause & 17 & 10.79 \\
Superficial gastroduodenal lesions & 15 & 6.47 \\
Gastric tumor & 9 & 4.32 \\
Peptic oesophagitis & 6 & 1.44 \\
Mallory Weiss syndrome & 2 & 0.72 \\
Angiodysplasia & 1 & 100 \\
Total & 139 &
\end{tabular}




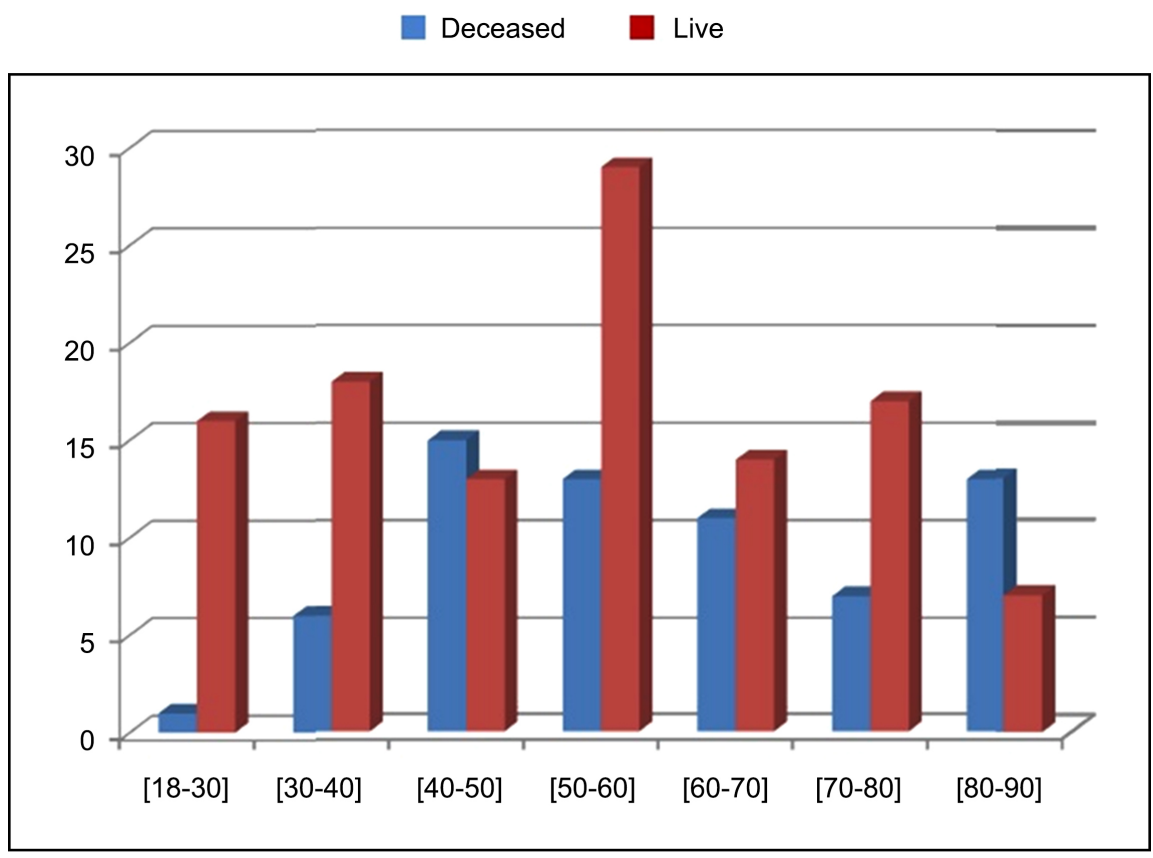

(OR: $9.79 ; 95 \% \mathrm{Cl}[1.24-76.83] ; p=0.003$ )

Figure 1. Distribution of patients by age.

$\mathrm{p}=0.3001)$. An initial haemoglobin higher than $7 \mathrm{~g} / \mathrm{dL}$ significantly reduced the risk of death (OR: $0.28 ; 95 \%$ CI [0.14 - 0.54]; $\mathrm{p}=0.0001$ ). When necessary, blood transfusion was performed in 122 patients (67.8\%), 55 of whom died compared to 58 patients; it significantly increased the risk of death (OR: 3.5; 95\% CI $[1.66-7.40] ; \mathrm{p}=0.0001$ ). Treatment with proton pump inhibitors (PPI) at 8 milligrams per hour was administered to 154 patients of whom 51 had died, significantly reduced the risk of death (OR: 0.36; $95 \%$ CI [0.15 - 0.84]; $\mathrm{p}=0.0191$ ). Hemorrhagic recurrence, observed in 17 patients, 3 of whom had died, was not a factor associated with death $(\mathrm{OR}=0.34 ; 95 \% \mathrm{CI}[0.09-1.23] ; \mathrm{p}=0.1003)$. In multivariate analysis, the risk factors for mortality were age between 30 and 60 years old, male sex and late hospitalisation (Table 3).

\section{Discussion}

The high mortality rate in our series is probably related to the lack of endoscopic haemostasis. It remains high between 17 and $40 \%$ in other African countries [12] [16] [17]. On the other hand, in the centres that perform endoscopic haemostasis, mortality is low [6] [8] [9] [10]. It was of 3\% in Gabon in 2018, around 5\% in France. In our study, the age of population, male sex, late hospitalisation beyond 24 hours were identified as risk factors for death during upper GI haemorrhages in multivariate analysis. Yoo Jim Lee et al. in South Korea and El Mekkaoui in Tunisia [18] [19] found excess mortality by upper digestive haemorrhage in patients over 65 years old probably related to a high frequency of co-morbidities in this age group. The majority of the Congolese population is young, with less co-morbidity, which may explain the absence of a link between deaths and 
Table 2. Different risk factors for death during upper digestive haemorrhages.

\begin{tabular}{|c|c|c|c|c|c|c|}
\hline & & Deceased (\%) & Alive (\%) & OR & IC $95 \%$ & $\mathrm{p}$ \\
\hline & $<30$ years & $1(1.52)$ & $17(14.91)$ & & & \\
\hline \multirow[t]{3}{*}{ Age } & $30-60$ years & $35(53.03)$ & $59(51.76)$ & 9.79 & {$[1.24-76.83]$} & 0.003 \\
\hline & $>60$ years & $30(45.45)$ & $38(33.33)$ & & & \\
\hline & female & $16(24.24)$ & $44(38.94)$ & & & \\
\hline \multirow[t]{2}{*}{ Sex } & & & & 2.03 & {$[1.03-4]$} & 0.0393 \\
\hline & male & $50(75.76)$ & $70(61.06)$ & & & \\
\hline \multirow{2}{*}{$\begin{array}{l}\text { Gastrotoxic } \\
\text { taking }\end{array}$} & yes & $30(45.45)$ & $68(59.65)$ & \multirow{2}{*}{0.56} & \multirow{2}{*}[0.30-1.03]{} & \multirow{2}{*}{0.0665} \\
\hline & no & $36(54.55)$ & $46(40.35)$ & & & \\
\hline \multirow{3}{*}{ Comorbidities } & yes & $27(40.91)$ & $38(33.33)$ & \multirow{3}{*}{1.38} & \multirow{3}{*}[0.74-2.59]{} & \multirow{3}{*}{0.3086} \\
\hline & & & & & & \\
\hline & no & $39(59.09)$ & $76(66.67)$ & & & \\
\hline \multirow{3}{*}{ Admission time } & within $24 \mathrm{H}$ & $4(6.06)$ & $33(28.95)$ & \multirow{3}{*}{6.30} & \multirow{3}{*}{ [2.12 - 18.72] } & \multirow{3}{*}{0.0009} \\
\hline & & & & & & \\
\hline & After $24 \mathrm{H}$ & $62(93.94)$ & $81(71.05)$ & & & \\
\hline \multirow{3}{*}{ Rockall score } & Less than 3 & $11(16.67)$ & $17(14.91)$ & \multirow{3}{*}{1.54} & \multirow{3}{*}[0.55-4.31]{} & \multirow{3}{*}{0.4062} \\
\hline & $3-8$ & $39(59.09)$ & $81(71.05)$ & & & \\
\hline & More than 8 & $16(24.24)$ & $16(14.05)$ & & & \\
\hline \multirow{3}{*}{ Haemoglobin } & less than 7 & $47(71.21)$ & $47(41.23)$ & \multirow{3}{*}{0.28} & \multirow{3}{*}[0.14-0.54]{} & \multirow{3}{*}{0.0001} \\
\hline & & & & & & \\
\hline & more than 7 & $19(28.79)$ & $67(58.77)$ & & & \\
\hline \multirow{2}{*}{$\begin{array}{c}\text { Blood } \\
\text { transfusion }\end{array}$} & Less than 6 & $33(60)$ & $54(81.8)$ & \multirow[b]{2}{*}{3.5} & \multirow[b]{2}{*}[1.66-7.40]{} & \multirow[b]{2}{*}{0.0001} \\
\hline & More than 6 & $22(40)$ & $13(18.2)$ & & & \\
\hline \multirow{3}{*}{$\mathrm{PPI}^{*}$ treatment } & yes & $51(72.2)$ & $102(89)$ & \multirow{3}{*}{0.36} & \multirow{3}{*}[0.15-0.84]{} & \multirow{3}{*}{0.0191} \\
\hline & & & & & & \\
\hline & no & $15(27.8)$ & $12(11)$ & & & \\
\hline \multirow{2}{*}{$\begin{array}{c}\text { Haemorragic } \\
\text { reccurence }\end{array}$} & yes & $3(4.55)$ & $14(12.28)$ & \multirow[b]{2}{*}{0.34} & & \\
\hline & no & $63(95.45)$ & $100(87.72)$ & & {$[0.09-1.23]$} & 0.1003 \\
\hline
\end{tabular}

*Proton pump inhibitors.

Table 3. Multivariate analysis of risk factors.

\begin{tabular}{cccc}
\hline & OR & IC 95\% & p \\
\hline Age between $30-$ 60 years old & 8.84 & {$[1.73-127.39]$} & 0.0139 \\
Male sex & 2.31 & {$[1.05-5.06]$} & 0.0366 \\
Late hospitalisation & 6.21 & {$[1.93-19.99]$} & 0.0022 \\
\hline
\end{tabular}


co-morbidities in our study. The male sex is unanimously described as a risk factor for death by many authors [1] [2] [18] [20]. The predominance in men of the main causes of upper digestive haemorrhage (peptic ulcer disease and cirrhosis) is probably the reason for this result, which may constitute an interpretation bias. The male gender alone cannot explain the higher risk of bleeding in men. Previous intake of gastrotoxic products is also described as being related to the risk of death during upper digestive haemorrhage [19] [21]. We have grouped together under the term gastrotoxic drugs such as anti-inflammatory drugs and anticoagulants that can cause bleeding or digestive bleeding. This could explain the lack of a link between upper digestive haemorrhages and death. Deby et al. in Congo [14], Lahimidani et al. [19] in Morocco found a high risk of death during upper GI haemorrhage in patients taking anti-inflammatory drugs. Late hospitalisation, on the other hand, has not often been evaluated in similar studies, probably because in developped countries or with a health insurance system, patients consult early. In our country, in case of illness, people often starts with self-medication before going to hospital, thus increasing the risk of death during digestive haemorrhages. Fréderic Prat et al. [22] found a 0.07 reduction in the risk of death from high-dose PPI's, which is comparable to our results. The effectiveness of proton pump inhibitors probably explains this protection during upper digestive haemorrhages. Therefore, they are the only non-surgical treatment available in our country for the management of upper digestive haemorrhages. Other authors [1] [2] confirm the reduced risk of death although proton pump inhibitors do not provide hemostasis. Patients aged between 30 and 60 years were the most frequent in our study and had a higher risk of death in case of upper digestive haemorrhage. This age group may explain the late delay in consultation observed in our study, self-medication most often with anti-inflammatory drugs, thus increasing the risk of death during upper digestive haemorrhages. Retrospective data collection was certainly a source of selection bias, but the large sample size and the study design (case-control) allow us to draw the relevant conclusions from this study.

\section{Conclusion}

Mortality related to upper digestive haemorrhages remains high in Brazzaville despite PPI treatment and blood transfusions that reduce the risk of death. The lack of endoscopic haemostasis is probably the explanation. Taking into account the risk factors for death identified during this study and the improvement of our technical platform by the acquisition of endoscopic haemostasis equipment will improve the practical management of upper digestive haemorrhages.

\section{Conflicts of Interest}

The authors declare no conflicts of interest regarding the publication of this paper.

\section{References}

[1] Zeitoun, J.-D., Chryssostalis, A. and Lefèvre, J. (2017) In Hepatology Gastroenterology 
Visceral surgery. 5th Edition. Vernazobres Grego, Paris, 552-559.

[2] Silvain, C., Borderie, C., Ripault, M.P., et al. (1998) Les hémorragies digestives. Encycl Médchir Gastroenterology, 12 p.

[3] Nahon, S., Hagège, H., Latrive, J.P., et al. (2012) Epidemiological and Prognostic Factors Involved in Upper Gastrointestinal Bleeding: Results of a French Prospective Multicenter Study. Endoscopy, 44, 998-1006. https://doi.org/10.1055/s-0032-1310006

[4] El Mekkaoui, A., Mellouki, I., Berraho, M.A., et al. (2011) Epidemiology, Etiology and Evolution of Upper Digestive Haemorrhages at the University Hospital of Fez, Morocco. Acta Endoscopica, 41, 337-343. https://doi.org/10.1007/s10190-011-0206-4

[5] Pateron, D. and Debuc, E. (2005) Management of an Upper Digestive Haemorrhage in the Emergency Setting. Emergency Medicine, 24, 29-39.

[6] Itoudi-Bignoumba, P.E., Manganga Moussavou, I.F. and Moussavou Kombila, J.B. (2019) Upper Digestive Haemorrhage at the Libreville University Hospital Centre: Clinical Aspects and Actual Management: about 210 Patients. The Jour Med Health Sci, 20, 20-22.

[7] Stanley, A.J. (2019) Management of Acute Upper Gastrointestinal Bleeding. BMJ, 364, Article ID: 1536. https://doi.org/10.1136/bmj.1536

[8] Gonzales-Gonzales, J.A., Vasquez-Elizondo, G., Garcia Compean, D., Gaytan-Torres, J.O., Flores-Rendon, A.R., et al. (2011) Predictors of In-Hospital Mortality in Patients with Non Variceal Upper Gastrointestinal Bleeding. Revista Española de Enfermedades Digestivas, 103, 196-203. https://doi.org/10.4321/S1130-01082011000400005

[9] Morales-Uribe, C.H., Sierra-Sierra, S., Hernandez-Hernandez, A.M., Arango-Durango, A.F. and Lopez, G.A. (2011) Upper Gastrointestinal Bleeding: Risk Factors for Mortality in Two Urban Centers in Latin America. Spanish Journal of Digestive Diseases, 103, 20-24. https://doi.org/10.4321/S1130-01082011000100004

[10] Lim, L.G., Ho, K.Y., Chan, Y.H., Teoh, P.L. and Khor, J. (2011) Urgent Endoscopy Is Associated xith Lower Mortality in High-Risk but Not Low-Risk Non Variceal Upper Gastrointestinal Bleeding. Edoscopy, 43, 462-463. https://doi.org/10.1055/s-0030-1256110

[11] Slim, R., Yaghi, C., Honein, K., et al. (2005) Upper Gastrointestinal Bleeding: Identification of Prognostic Factors. The Lebanese Medical Journal, 3,143-150.

[12] Sombié, R., Tiendrébéogo, A., Guingané, A., Hagège, H., Lesgourgues, B., Lamy, V., et al. (2015) Upper Digestive Haemorrhage: Epidemiological Aspects and Prognostic Factors in Burkina Faso (West Africa). Journal Africain d Hépato-Gastroentérologie, 9, 154-156. https://doi.org/10.1007/s12157-015-0610-Z

[13] Diakité, M., Toth'o, A., Assi, C., Bathaix, F., Koné, S., Bangoura, D., et al. (2015) Epidemiology and Pronstic Factors of Upper Digestive Haemorrhage in Côte d'Ivoire. Journal Africain d Hépato-Gastroentérologie, 10, 1-5. https://doi.org/10.1007/s12157-015-0644-2

[14] Gassaye, D., Atipo Ibara, B.I., Ndolo-Mbika, A.B., et al. (2004) Les hémorragies digestives et les médicaments anti-inflammatoires au CHU de Brazzaville. Bulletin de la Société de Pathologie Exotique, 97, 323-324.

[15] Ibara, J.-R., Atipo-Ibara, B.I., Bouangui Bazolana, S. and Itoua-Ngaporo, A. (2007) Epidemiological, Clinical and Endoscopic Aspects of Upper Digestive Haemorrhages in Hospitals in Brazzaville. Burkina Medical, 10, 49-56.

[16] Diarra, M., Soucko-Diarra, A., Dolo, M., et al. (2007) Les hémorragies digestives hautes aiguës: Expérience d'un milieu rural. Acta Endoscopica, 37, Article No. 321. 
https://doi.org/10.1007/BF02961922

[17] Kodjoh, N., Hountondji, A. and Addra, B. (1992) Upper Digestive Haemorrhage and Oeso-Gastro-Duodenal Pathology in a Department of Internal Medicine in a Tropical Environment. Black African Medicine, 39, 25-30.

[18] Lee, Y.J., Min, B.R., Kim, E.S., Park, K.S., Cho, K.B., et al. (2016) Predictive Factors of Mortality within 30 Days in Patients with Nonvariceal Upper Gastrointestinal Bleeding. The Korean Journal of Internal Medicine, 31, 54-64. https://doi.org/10.3904/kjim.2016.31.1.54

[19] Lahmidani, N., Zeroune, W., Melloki, I., El Yousfi, M., Aqodad, N,. et al. (2012) Haemorrhagic Bulbar Ulcer and Non-Steroidal Anti-Inflammatory Drugs: How Serious Is the Haemorrhagic Event? Journal Africain d Hépato-Gastroentérologie, 6, 193-195. https://doi.org/10.1007/s12157-012-0396-1

[20] El Mekkaoui, A., Saada, K., Mellouki, I., et al. (2012) The Epidemiological Difference in Upper Digestive Haemorrhages between Men and Women. The Pan African Medical Journal, 12, 94-102.

[21] Duroy, E. and De la Gastine, B. (2011) Severe Haemorrhages under Antivitamin K Treatment with Prothrombotic Complexes: Retrospective Study in 2008. La Revue de Médecine Interne, 32, 529-536. https://doi.org/10.1016/j.revmed.2011.02.021

[22] Frédéric, P. (2004) Management of Digestive Haemorrhages of Ulcerous Origin in 2004. Hepato-Gastro and Oncologie Digestive, 11, 95-97. 